\title{
RISCO, VULNERABILIDADE FÍSICA À EROSÃO COSTEIRA E IMPACTOS SÓCIO-ECONÔMICOS NA ORLA URBANIZADADO MUNICÍPIO DE MARICÁ, RIO DE JANEIRO
}

\author{
Flavia Moraes Lins-de-Barros \\ Laboratório de Geografia Marinha da UFRJ. Doutoranda em Geografia - PPGG/UFRJ \\ flaviamlb@br.inter.net
}

\begin{abstract}
Resumo
O estudo da erosão costeira no município de Maricá, no estado do Rio de Janeiro, aponta para a problemática resultante da ausência de um planejamento urbano para as orlas que considere de maneira adequada a vulnerabilidade física e os riscos envolvidos. Nos anos de 1995, 1996 e 2001 fortes ondulações atingiram os litorais sul e sudeste do Brasil provocando no litoral de Maricá graves danos sobre as construções. Os prejuízos financeiros em função das destruições, desvalorização imobiliária e das obras realizadas atingiram uma cifra de aproximadamente $\mathrm{R} \$ 3$ milhões. O presente artigo visa discutir o problema da erosão costeira no município de Maricá através da avaliação dos impactos socioeconômicos e da definição de áreas críticas e de risco potencial à erosão costeira. Os mapeamentos do grau de vulnerabilidade e risco demonstraram predominância ao longo do arco praial de segmentos com risco elevado e muito elevado em função da baixa resistência do litoral aos eventos erosivos, elevada exposição às tempestades, elevada densidade de construção na orla e casas e quiosques posicionados na escarpa ou na berma da praia. Este resultado combinado à caracterização das praias quanto ao grau de danos sofridos, aos tipos de adaptação e ao prejuízo financeiro permitiu definir áreas especiais para o planejamento na orla de Maricá, contribuindo com sugestões de possíveis medidas que visem reverter a atual situação.
\end{abstract}

Palavras-Chave: Erosão costeira; Risco; Vulnerabilidade.

\begin{abstract}
The investigation of coastal erosion of Maricá County at Rio de Janeiro State indicates the absence of an urban planning that considers appropriately the physical vulnerability and the risks involved. In 1995, 1996 and 2001 strong storms reached the South and Southeast coastline of Brazil causing severe destructions of houses, kiosks and streets at Maricá ss shoreline. The financial losses due to proprieties destruction and devaluation added to the costs of the defense structures construction was about R \$ 3 millions (about U\$ 1.2 thousands). The present paper discusses the coastal erosion problem at Maricá County through the evaluation of the socioeconomic impacts and the identification of critical and potential risk areas. The mapping of the degree of vulnerability and risk indicated the predominance of endangered segments with high to very high risk as a consequence of the low resistance of the shoreline to storm events, the direct exposition to storms, and inadequate location of the houses and kiosks, which are very close to the active profile. The result together with to the beaches characterization concerning the degree of damages, the types of the adaptations and the financial losses allowed the definition of special areas for urban planning at Maricá shoreline contributing to mitigations suggestions, in order to the present situation.
\end{abstract}

Key Words: Coastal erosion; Risk, Vulnerability.

Introdução

O problema da erosão costeira vem sendo observado em diferentes locais do mundo, sendo considerado atualmente um fenômeno global (BIRD, 1993). Com a intensa urbanização das orlas, principalmente a partir da década de 1970, este problema passou a ser tratado não apenas pelos estudos voltados para a compreensão dos processos físicos, mas também sob um enfoque sócio-econômico tendo em vista os impactos causados nas construções urbanas. Com isso, os prejuízos financeiros decorrentes dos danos em construções situadas inadequadamente no espaço dinâmico das praias trouxeram para o meio acadêmico, assim como para os debates políticos, a necessidade de se pensar o planejamento urbano para as orlas costeiras de maneira integrada à noção atual de gerenciamento costeiro.

O litoral do município de Maricá, no estado do Rio de Janeiro, representa um exemplo desta problemática envol- 
vendo ocupação urbana das orlas e vulnerabilidade física à erosão costeira. A ausência de um planejamento com limites de proteção da orla adequados resultou na ocupação desordenada ao longo de praticamente todo o arco praial, com construções posicionadas próximas ao perfil ativo da praia. Tal situação somada às características naturalmente frágeis do litoral de Maricá resultou em graves danos sobre as construções da orla após as fortes ressacas que atingiram o litoral sul e sudeste do Brasil nos anos de 1995, 1996 e 2001. Os prejuízos financeiros em função das destruições, desvalorização imobiliária e das obras realizadas após a tempestade ocorrida em maio de 2001 atingiu uma cifra de aproximadamente R\$ 3 milhões (LINS-DE-BARROS, 2005).

O presente artigo tem como objetivo principal discutir o problema da erosão costeira no município de Maricá e o seu impacto sobre a orla urbanizada, destacando-se os danos, prejuízos financeiros e adaptações da população.

É proposta uma classificação quanto ao grau de risco à erosão costeira em função da vulnerabilidade física e das características da ocupação urbana da orla. Busca-se com isso identificar as áreas críticas e de risco potencial à erosão costeira que demandem diferentes medidas de planejamento urbano. A discussão suscitada ao longo do artigo visa, também, apontar os aspectos sócio-econômicos envolvidos na questão da erosão costeira, assim como a importância de se considerar as áreas de risco na elaboração de planejamentos urbanos para as orlas.

\section{Caracterização da Área de Estudo}

O município de Maricá localiza-se a leste da Baía de Guanabara entre os municípios de Niterói e Saquarema. A área de estudo engloba as praias de Itaipuaçu, Francês, Barra de Maricá, Guaratiba, Cordeirinho e Ponta Negra, compreendendo uma área de aproximadamente $24 \mathrm{~km}$ (figura 1).

Segundo a classificação proposta por Muehe e Valentini (1998), Maricá pertence à chamada Região dos Lagos no litoral Sul, cuja paisagem é marcada pela presença de extensos arcos praiais associados a cordões litorâneos

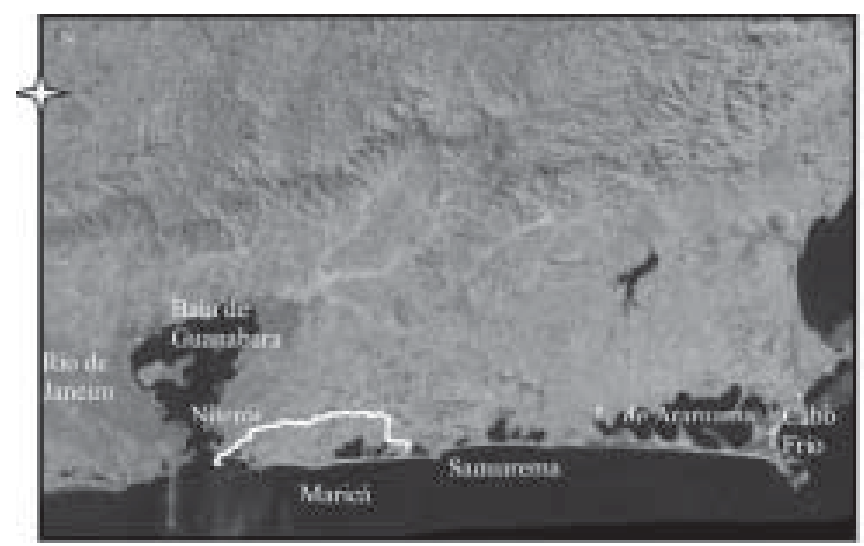

Figura 1: Imagem de Satélite com a localização do Município de Maricá. Fonte: Embrapa (CD). transgressivos. Sua orientação leste-oeste e a quase inexistência de proteções naturais torna este litoral exposto às fortes tempestades provenientes do quadrante sul.

A partir da década de 1970, com a construção da ponte Rio-Niterói (concluída em 1976) e, em 1996 com a auto-estrada Via-Lagos, todos os municípios da Região dos Lagos sofreram forte incremento populacional. Na década de 1990 o município de Maricá apresentou a quinta maior taxa de crescimento do estado do Rio de Janeiro (IBGE, 2000). Buscando estabelecer um limite de proteção da orla de Maricá o Plano de Desenvolvimento Urbano do município estabeleceu em 1984 uma zona non-aedificandi para a orla. A faixa definida, no entanto, não ultrapassa a própria faixa de areia, sendo, portanto, considerada completamente inadequada. Atualmente, com exceção do segmento que corresponde à Área de Proteção Ambiental (APA) considerada integralmente como non-aedificandi pelo decreto $n^{\circ} 7320$ de 1984, o estreito cordão litorâneo de Maricá vem passando por intenso processo de expansão urbana.

\section{Metodologia}

A orla do município de Maricá foi classificada quanto ao grau de danos sofridos durante a tempestade que ocorreu em maio de 2001, quando foram observadas as maiores destruições. Para a classificação quanto ao grau de danos foram realizados trabalhos de campo tendo sido percorrida a pé toda a orla do município, com exceção do trecho sem urbanização. Através de observações e entrevistas foi possível classificar o grau de danos sofridos pelas propriedades, quiosques e avenidas. Cada um dos segmentos identificados foi localizado por meio de um GPS e posteriormente mapeado a partir do programa de mapeamento ArcView 3.2 da ESRI.

As adaptações foram analisadas em termos de obras de proteção ou recuperação. Os diferentes tipos de obras foram localizados por meio de um GPS e classificados de acordo com o material utilizado.

Os prejuízos financeiros decorrentes dos danos e do custo para realização de obras foram obtidos através de entrevistas com agentes imobiliários e proprietários das casas. A partir das informações dos moradores e da estimativa do valor das casas a partir do valor venal $(\mathrm{R} \$ / \mathrm{m})$ fornecido pela prefeitura foi realizado um cálculo da desvalorização (considerando $100 \%$ no caso das construções completamente destruídas e de $50 \%$ no restante da orla) para o arco praial entre a praia da Barra de Maricá e Ponta Negra.

A orla de Maricá foi classificada ainda quanto à vulnerabilidade potencial do cordão litorâneo e ao grau de instabilidade local. Baseando-se em conceitos e metodologias de diversos autores (Bush et. al., 1999; Dal Cin e Simeoni, 1994; Dolan e Walker, 2004; Morton, 2002) os seguintes indicadores foram selecionados para avaliação da vulnerabilidade potencial do cordão:

1. evolução da linha de costa: comparação de 
fotografias aéreas dos anos de 1972 e 1999 na escala de 1:8.000 (fornecidas pela Companhia Elétrica do Rio de Janeiro - CERJ e pelo Centro de Dados do estado do Rio de Janeiro - CIDE) e comparação de perfis transversais realizados nos anos de 1974 e 2004;

2. refração das ondas: modelagem da propagação das ondas de tempestade realizada através do programa Mike 21 da DHI Water \& Environment a partir dos dados batimétricos;

3. características do cordão litorâneo (altura, largura e marcas de transposição pelas ondas).

Os indicadores e respectivas variáveis escolhidos para classificar a instabilidade local foram:

1. resistência: cobertura vegetal, granulometria e dunas;

2. exposição: refração das ondas e presença de proteções naturais (ilhas, promontórios);

3. resiliência: capacidade de auto-recuperação dos perfis de praia ${ }^{1}$.

A análise do risco, por sua vez, conforme os conceitos apresentados por Dal Cin e Simeoni (1994) e Dolan e Walker (2004) deve considerar a maior ou menor exposição das estruturas ou da população a eventos que podem causar danos. Desta forma, foram considerados para a classificação do grau de risco a instabilidade local combinada à densidade de construção na orla e à posição das construções em relação às feições da praia ao longo do perfil transversal. Estes dois últimos indicadores urbanos, assim como os indicadores e variáveis de instabilidade local, foram analisados através de trabalhos de campo e da interpretação das fotografias aéreas de 1999.

Finalmente, a partir da análise do grau de danos e de risco ao longo do arco praial foi possível identificar áreas especiais para o planejamento urbano.

\section{Resultados}

\subsection{Vulnerabilidade Física}

A avaliação dos diferentes indicadores apontaram para a elevada vulnerabilidade potencial do cordão em função principalmente da tendência de recuo da linha de costa observada (recuo médio de 15 metros nos últimos 30 anos) e da elevada altura e convergência da energia das ondas na zona de arrebentação em quase todas as praias. Apenas na praia do Francês e em parte da APA de Maricá ocorre diminuição da altura das ondas em função da influência das ilhas Maricás. Outras características como a transposição do cordão litorâneo pelas ondas de tempestade, a pequena cobertura vegetal e a quase inexistência de dunas reforçam a constatação da elevada vulnerabilidade potencial.

No entanto, a análise mais local da resistência e exposi- ção revelou diferentes graus de instabilidade local ao longo do arco praial (tabela 1; figura 1).

São destacados três principais segmentos: a praia de Itaipuaçu; a praia do Francês e a APA de Maricá; e o trecho entre as praias da Barra de Maricá e Ponta Negra. Este último merece destaque por apresentar em toda sua extensão instabilidade local muito elevada. Tal característica reflete a inexistência de dunas, a ausência de cobertura vegetal, a granulometria relativamente mais fina e a exposição elevada ou muito elevada às ondas. A praia de Itaipuaçu apresenta alternância entre instabilidade local muito elevada e elevada

Tabela 1: Indicadores e variáveis associadas ao grau de instabilidade local.

\begin{tabular}{c|c|c|c}
\hline $\begin{array}{c}\text { Instabilidade } \\
\text { Local }\end{array}$ & Resistência & $\begin{array}{c}\text { Grau de } \\
\text { Exposição }\end{array}$ & Transposição \\
\hline \multirow{4}{*}{ Muito Elevada } & muito baixa & muito elevado & ausente \\
\cline { 2 - 4 } & baixa & muito elevado & ausente \\
\cline { 2 - 4 } & muito baixa & elevado & ausente \\
\cline { 2 - 4 } & baixa & elevado & presente \\
\hline \multirow{4}{*}{ Elevada } & baixa & elevado & ausente \\
\cline { 2 - 4 } & moderada & muito elevado & ausente \\
\cline { 2 - 4 } & muito baixa & moderado & ausente \\
\cline { 2 - 4 } & baixa & moderado & ausente \\
\cline { 2 - 4 } & moderada & elevado & ausente \\
\hline \multirow{4}{*}{ Moderada } & alta & elevado & ausente \\
\cline { 2 - 4 } & moderada & moderado & ausente \\
\hline \multirow{2}{*}{ Fraca } & moderada & fraco & ausente \\
\cline { 2 - 4 } & alta & moderado & ausente \\
\hline
\end{tabular}

em função da presença em alguns trechos de cobertura vegetal densa ou esparsa e granulometria muito grossa ou grossa. No caso da praia do Francês e da APA de Maricá predomina a instabilidade local fraca visto que aí se encontra um campo de dunas com vegetação bem desenvolvida. Além disso, a presença das ilhas Maricás é responsável neste segmento pela menor exposição às ondas. A análise de perfis transversais realizados nas praias de Itaipuaçu, Francês e Barra de Maricá revelou ainda que as praias com maior instabilidade local segundo os indicadores descritos apresentaram também elevada variabilidade do perfil e grande desvio padrão da largura o que, segundo Muehe e Vallentini (1998) indica instabilidade geomorfológica. A praia do Francês, por exemplo, possui o menor desvio padrão das larguras dos perfis transversais e, portanto, maior estabilidade do que a praia da Barra de Maricá com valores elevados de variabilidade vertical e do desvio padrão das larguras.

\subsection{Risco e Danos}

Na figura 2 observa-se o resultado da classificação da orla quanto ao grau de risco em função da instabilidade local e da densidade e posição das construções no perfil transversal.

Nota-se a predominância em todo o arco praial urbanizado 


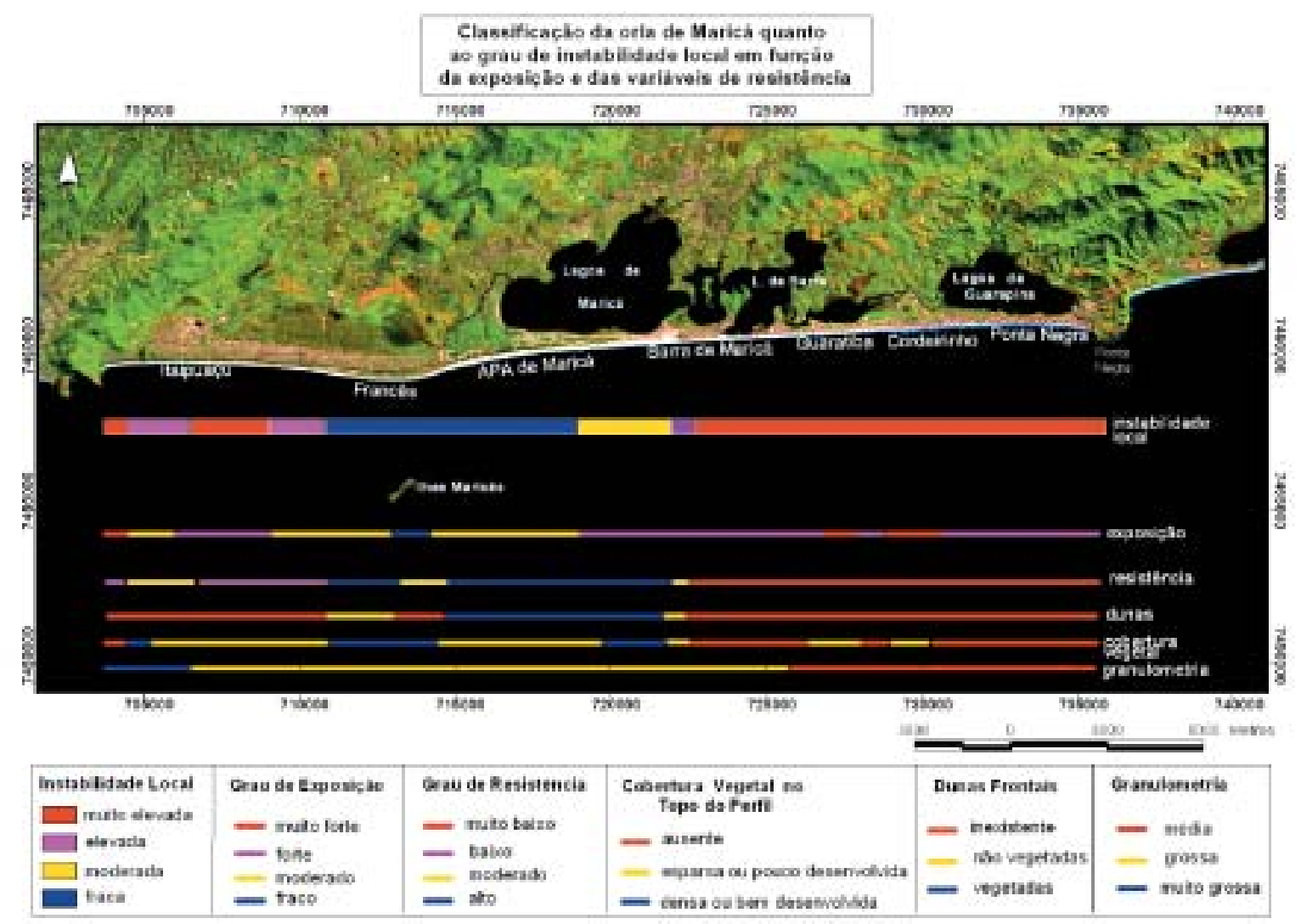

Figura 1: Classificação da orla do município de Maricá quanto à Instabilidade Local e indicadores associados.

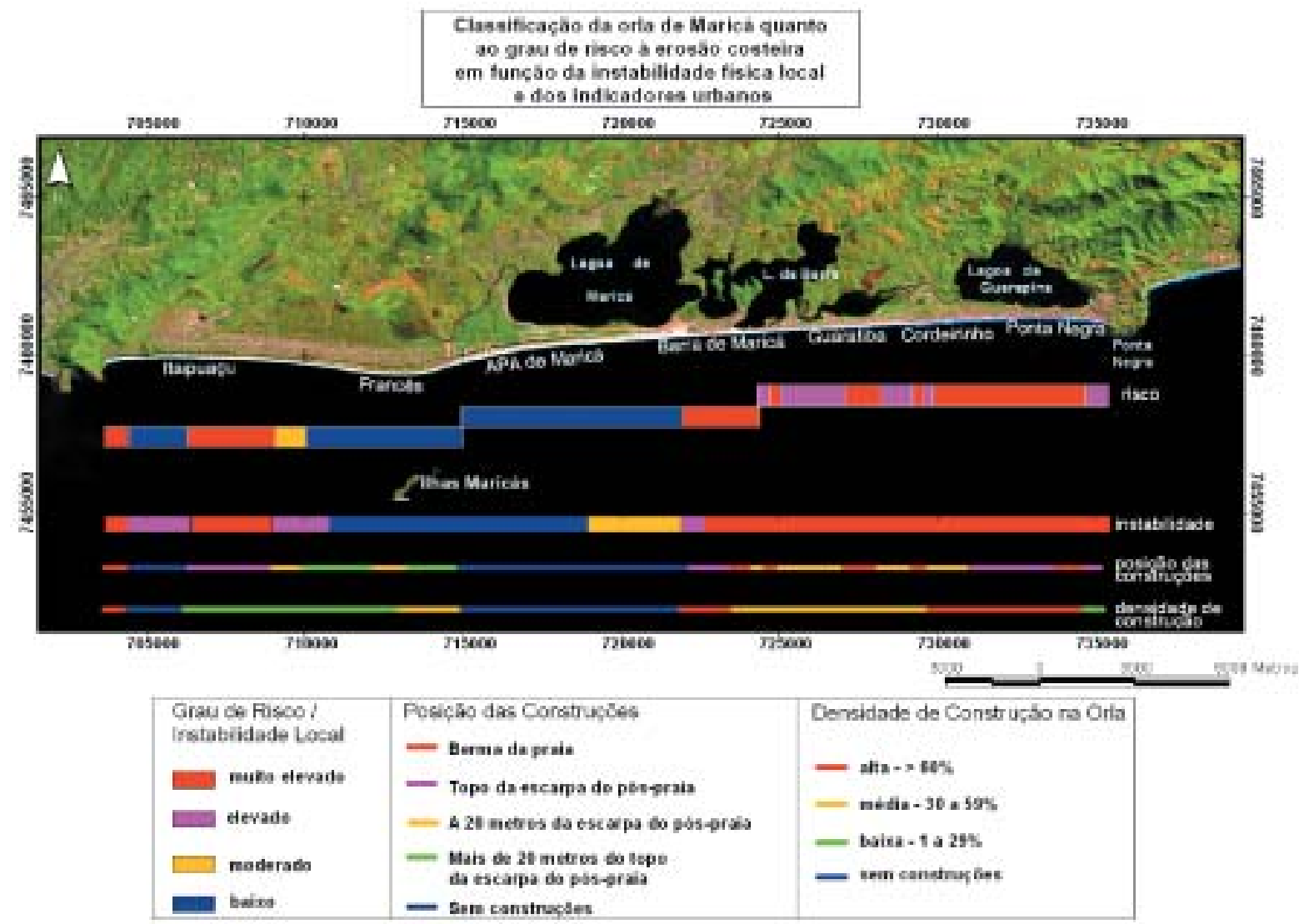

Figura 2: Classificação do Litoral de Maricá quanto ao grau de risco em função da instabilidade local à erosão costeira e das características da ocupação urbana da orla. 
Tabela 2: Descrição do Grau de Danos.

\begin{tabular}{c|l}
\hline Grau de Danos & \multicolumn{1}{c}{ Descrição } \\
\hline Ausente & \multicolumn{1}{c}{ segmentos sem construções. } \\
\hline Fraco & $\begin{array}{l}\text { danos muito pequenos do acesso às casas e quiosques; } \\
\text { alagamentos das casas sem destruição. }\end{array}$ \\
\hline Moderado & $\begin{array}{l}\text { destruição parcial da avenida litorânea dificultando a } \\
\text { circulação de veículos e acesso às casas. }\end{array}$ \\
\hline Forte & $\begin{array}{l}\text { destruição total da avenida litorânea; destruição parcial } \\
\text { dos muros das casas. }\end{array}$ \\
\hline Muito Forte & $\begin{array}{l}\text { destruição total ou de grande parte dos quiosques, } \\
\text { muros ou casas. }\end{array}$ \\
\hline
\end{tabular}

do risco elevado e muito elevado. Apresentam risco muito elevado as praias da Barra de Maricá, Ponta Negra e segmentos da praia de Itaipuaçu. A praia de Guaratiba embora possua instabilidade local muito elevada foi considerada na maior parte de sua extensão como de risco elevado em função da densidade de construção menor e da posição das casas e quiosques relativamente afastadas da escarpa da pós-praia. A praia do Francês, por outro lado, foi classificada como sendo de risco baixo visto que, além de apresentar instabilidade local fraca, possui densidade de construções baixa e posicionadas a 20 metros ou mais da escarpa da póspraia.

Os danos sofridos pelas construções do município de Maricá após fortes tempestades refletiram, portanto, uma situação de vulnerabilidade física e risco predominantemente muito elevados. A partir da definição do grau de danos (tabela 2) é possível afirmar que os danos mais fortes ocorreram nas praias da Barra de Maricá e Ponta Negra o que corresponde com o resultado de risco muito elevado encontrado para estas duas praias (foto 1).

A praia de Guaratiba apresentou dano moderado a forte tendo sido a Avenida Litorânea a principal estrutura urbana danificada. Este dado demonstra que a aparente pequena diferença entre os segmentos de risco muito elevado e elevado pode significar uma importante diferença em relação ao grau de danos. Além disso, tendo em vista que as principais distinções entre esta praia e as praias da Barra de Maricá e Ponta Negra são as características urbanas, é possível afirmar que são estes os fatores mais importantes para a compreensão da intensidade dos danos. É importante, no entanto, ressaltar, que uma análise mais local da cobertura vegetal revela também que a praia de Guaratuba apresenta vegetação mais bem desenvolvida em muitos trechos o que pode, portanto, contribuir para amenizar os danos (LINS-DE-BARROS, 2005).

$\mathrm{Na}$ praia de Itaipuaçu, embora alguns muros e parte da avenida litorânea tenham sido destruídos (Jornal O DIA, 1995; 1996), os danos não foram tão fortes quanto nas duas primeiras praias descritas acima. Na praia do Francês as construções não foram atingidas pelas ondas, com exceção de dois quiosques localizados na berma da praia os quais tiveram pequenos danos.

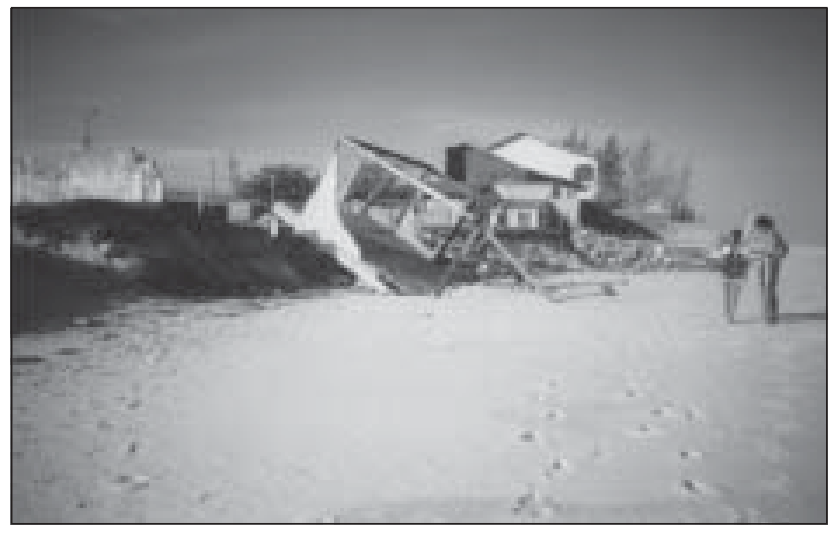

Foto 1: Praia da Barra de Maricá. Dano muito forte. Destruição total da casa. Foto: Dieter Muehe.

\subsection{Adaptações e Prejuízos}

Os proprietários das casas e quiosques localizados na orla de Maricá realizaram diversos tipos de obras, sendo esta a principal maneira de adaptação observada. Os tipos de obras mais comuns foram recuperação (quando apenas foi recuperado o que foi danificado), aterros (areia, entulhos ou barro) e muros (tijolos, concreto, anéis de manilha ou enrocamento) (LINS-DE-BARROS et al., 2003). Na praia de Itaipuaçu apenas no segmento com dano muito forte foi observada obra de proteção. No restante desta praia e na praia do Francês a menor densidade urbana e a predominância de danos fracos ou ausentes resultou na inexistência de obras de qualquer tipo. Ao contrário, entre Barra de Maricá e Ponta Negra houve uma enorme quantidade e variedade de obras. Neste trecho do litoral aproximadamente $42 \%$ de sua extensão possui obras.

A destruição das construções e a realização destas obras no trecho compreendido entre Barra de Maricá e Ponta Negra representaram prejuízos econômicos diretos e indiretos respectivamente. Os valores mostram que no trecho de aproximadamente $14 \mathrm{~km}$ houve prejuízo financeiro de mais de $\mathrm{R} \$ 2$ milhões, o que equivale a um prejuízo médio de aproximadamente de 143 mil reais $/ \mathrm{km}$ (tabela 3 ).

Os danos sofridos pelas construções foram responsáveis ainda pela desvalorização das casas e terrenos. Um aspecto freqüentemente apontado pelos moradores como forte fator de desvalorização das casas na orla foi a destruição do acesso às casas. Considerando uma desvalorização de $50 \%$, foi encontrado o valor médio de aproximadamente

Tabela 3: Prejuízo econômico total considerando os prejuízos diretos com a destruição e os prejuízos indiretos com a realização de obras.

\begin{tabular}{c|c|c}
\hline \multicolumn{3}{c}{ Prejuízo Econômico Total (R\$) - Barra de Maricá a Ponta Negra } \\
\hline Prejuízo Direto & Prejuízo Indireto & \multirow{2}{*}{ Prejuízo Total } \\
\hline Destruição total das casas & Custo total das obras realizadas & \\
\hline $1.560 .000,00$ & $534.000,00$ & $2.090 .000,00$ \\
\hline
\end{tabular}


200 mil reais / km. Este valor somado aos prejuízos indiretos pela realização de obras atinge a cifra de 235 mil reais / $\mathrm{km}$. O valor total do prejuízo, considerando as obras realizadas e a desvalorização foi de aproximadamente R \$ 3 milhões (aproximadamente U\$1.2 milhões). Deste total mais de $80 \%$ corresponde ao prejuízo causado pela desvalorização o que demonstra a importância deste processo.

No entanto, tal desvalorização foi provavelmente um problema mais presente nos dois primeiros anos após a ressaca de 2001 quando ainda era possível observar na praia alguns quiosques, casas e ruas destruídos. Atualmente alguns morados afirmam que as casas estão voltando a se valorizar Especificamente na praia de Itaipuaçu todos os moradores entrevistados afirmaram que não está ocorrendo desvalorização, ao contrário, os terrenos e as casas da praia estão valorizando devido ao intenso crescimento urbano. Nesta praia as ressacas mais fortes com destruição da Avenida Litorânea e de diversos muros de casas ocorreram há cerca de dez anos atrás. No ano de 1996 nove imóveis foram abandonados depois de uma ressaca severa no extremo oeste desta praia e casas no valor de $\mathrm{R} \$ 25 \mathrm{mil}$ passaram a custar apenas $\mathrm{R} \$ 5$ mil (Jornal O DIA, 1996).

Este dado sugere que depois de decorrido um determinado tempo, a tendência "normal" de valorização das propriedades da orla é retomada. Desta forma, quatro anos após a ressaca do ano de 2001 diversos entrevistados afirmaram que está ocorrendo um processo, mesmo que lento, de revalorização nas praias entre Barra de Maricá e Ponta Negra e que em Itaipuaçu, após 10 anos das fortes ressacas, o processo de valorização é uma realidade. Portanto, pode-se afirmar que, caso não ocorra outra tempestade excepcionalmente forte toda a orla deve estar em processo de valorização dentro de cinco anos. O gráfico a seguir (figura 3) representa um modelo esquemático deste processo de valorização / desvalorização das propriedades ao longo do tempo.

\section{4 Áreas Críticas, Áreas de Risco Potenciale Áreas Latentes}

As áreas definidas como especiais para planejamento foram:

Áreas críticas - áreas com risco elevado ou muito elevado e danos fortes ou muito fortes;

Áreas de risco potencial - com instabilidade local elevada ou muito elevada e danos predominantemente moderados a fracos. Apresentam construções mais afastadas da praia ou inexistentes, porém, possuem tendência de expansão urbana e aumento da densidade de construções o que pode levar a ocupação do topo da escarpa da praia e de sua berma;

Áreas latentes - apresentam instabilidade local fraca, densidade de construção baixa com predominância de casas e quiosques afastados da praia. Não possuem forte pressão de uso ou indícios de tendência de ocupação em um futuro próximo.
Processo de valorizaçāo e desvalorização em uma praia com ocorrência de ressacas

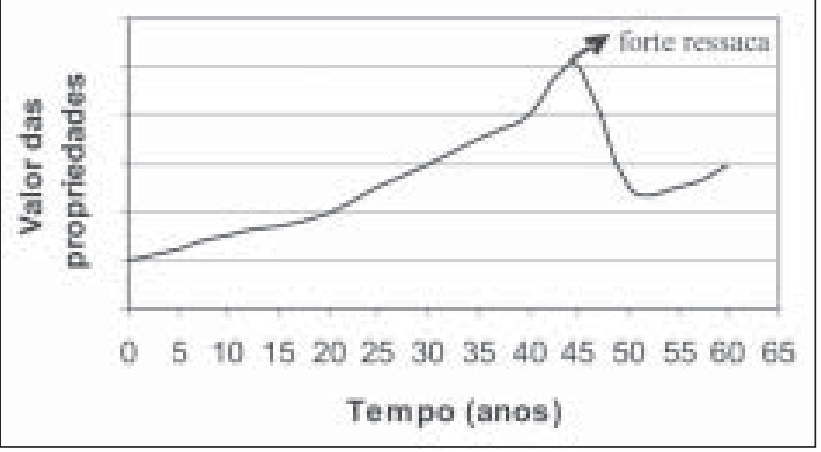

Figura 3: Modelo esquemático representando a valorização das propriedades da orla ao longo dos anos e a interrupção deste processo no momento em que tal litoral é atingido por forte ressaca responsável por danos nas construções. O processo de desvalorização que se segue permanece por aproximadamente 5 anos quando observa-se nova re-valorização.

Assume-se que as áreas na orla atualmente desocupadas que se encontram muito próximas às áreas com densidade de construção média ou alta possuem tendência de urbanização em um futuro próximo, tendo em vista a tendência de crescimento urbano do município e a valorização imobiliária principalmente na praia de Itaipuaçu. Estas áreas, quando localizadas em segmentos com instabilidade local elevada ou muito elevada, são consideradas, portanto, como áreas de risco potencial. Observa-se, com esta classificação, trechos da praia de Itaipuaçu, a praia de Guaratiba e o extremo oeste de Ponta Negra (Figura 4).

A praia do Francês, com pequena densidade de construção, casas a mais de 20 metros da escarpa da pós-praia e instabilidade fraca é considerada como área latente. Com a mesma classificação a APA de Maricá, além de apresentar instabilidade local predominantemente fraca, não possui construções e nem tendência de ocupação por se tratar de uma zona non-aedificandi. Finalmente, como áreas críticas onde devem ser tomadas ações corretivas, destacam-se as praias de Itaipuaçu, Barra de Maricá e Ponta Negra. É importante ressaltar que mesmo as áreas consideradas latentes encontram-se em um contexto de elevada vulnerabilidade potencial em função das características de refração das ondas e da tendência de recuo da linha de costa, além da própria fragilidade intrínseca do cordão litorâneo.

\section{Discussão}

Os resultados encontrados demonstraram a necessidade de elaboração de medidas de planejamento urbano para a orla de Maricá. A atualização do Plano de Desenvolvimento 


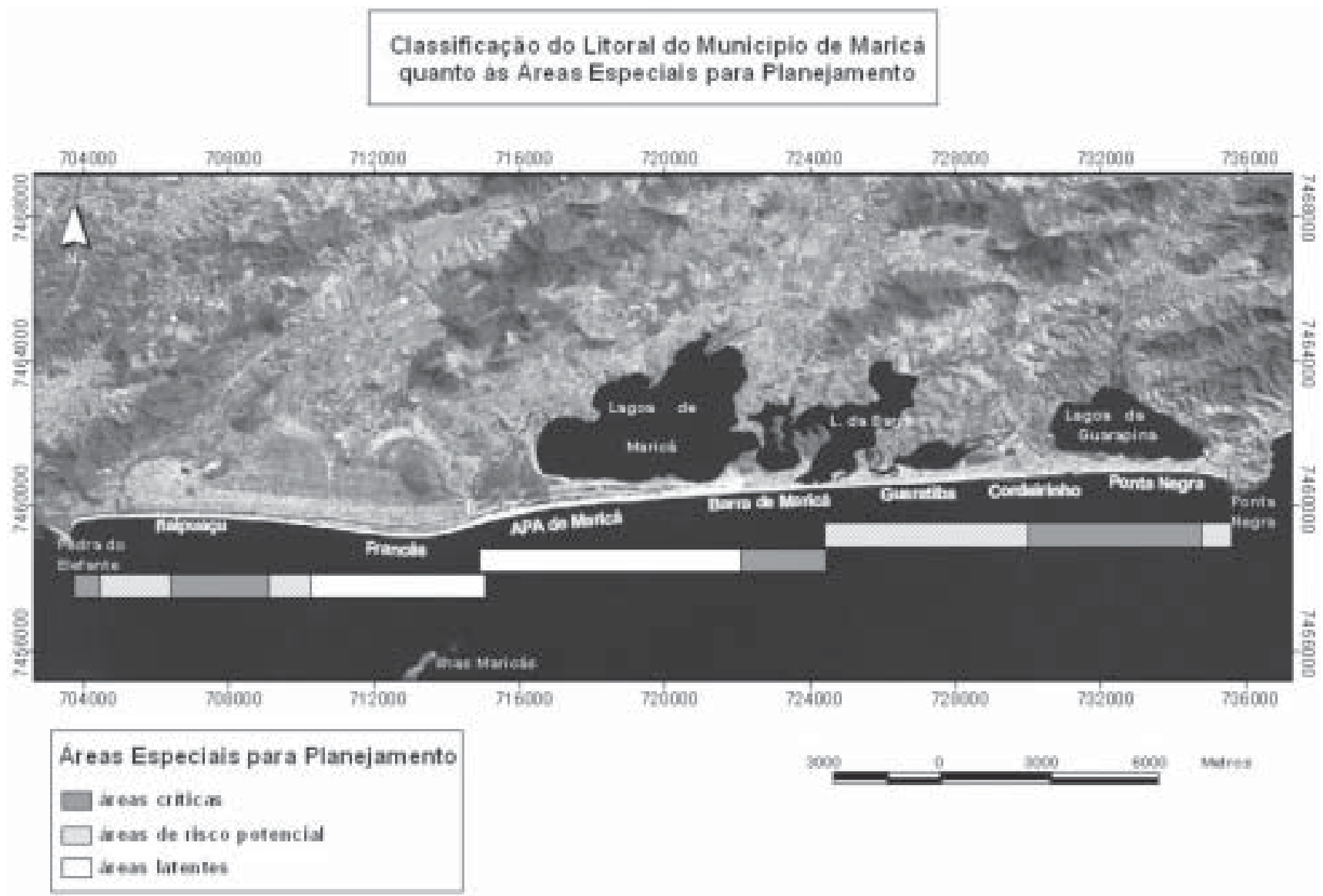

Figura 4: Classificação do litoral de Maricá quanto às áreas especiais para planejamento.

do Município de Maricá visando a delimitação de uma faixa de proteção costeira adequada, como proposto por Muehe (2001), torna-se prioridade para as áreas consideradas de risco potencial e latentes. Nas áreas críticas, onde a ocupação urbana da orla é mais densa, devem ser tomadas outras medidas como a proibição de construções de varandas, muros, quiosques ou deques na berma da praia. Tais medidas podem levar aos poucos a um rearranjo espacial e de uso da ocupação da orla revertendo a situação de risco muito elevado atualmente vivenciada pela maioria das construções.

\section{Conclusões}

De modo geral, a análise integrada dos diferentes indicadores considerados permitiu apontar as diferentes dimensões inseridas na questão da erosão costeira no município de Maricá. O resultado encontrado indicou que a metodologia utilizada pode ser adequada para a classificação da orla quanto à vulnerabilidade física e ao grau de risco, assim como na identificação de áreas especiais para planejamento.

Os resultados apontam, ainda, para as consequiências sócioeconômicas negativas decorrentes da falta de planejamento e ordenamento da ocupação urbana na zona costeira ressaltando principalmente os elevados prejuízos financeiros e a desvalorização imobiliária das orlas em função da percepção do risco.

\section{Agradecimentos}

À CAPES pela bolsa concebida durante os dois anos de mestrado (2003/2004); ao CNPq pelo apoio ao projeto Geomorfologia e processos morfodinâmicos da plataforma continental interna e ante-praia no estado do Rio de Janeiro desenvolvido pelo Laboratório de Geografia Marinha do Departamento de Geografia da UFRJ; ao Prof. Dr. Dieter Muehe pela orientação e incentivo.

\section{Referências Bibliográficas}

Bird, E. (1993) Submerging Coasts - The effects of a Rising Sea Level on Coastal Environments. John Wiley $\&$ Sons. Earthwatch, $184 \mathrm{p}$.

Bush, D. M.; Neal, W.; Young, R; Pilkey, O. (1999) Utilization of Geoindicators for Rapid Assessment of CoastalHazard Risk and Mitigation. Ocean and Coastal Management, v. 42. Ed. Elsevier: 647-670.

Dal Cin, R.; Simeoni, U. (1994) A Model for Determining the Classification, Vulnerability and Risk in the Southern Coastal Zone of the Marche (Italy). 
Journal of Coastal Research. Florida, 10 (1):18-29.

Dolan, A. H.; Walker, I. J. (2004) Understanding vulnerability of coastal communities to climate change related risks. Journal of Coastal Research, Special Issue. Brasil, 39 (No prelo)

Fundação IBGE (2000) Sinopse Preliminar do Censo Demográfico. XI recenseamento Geral do Brasil, Disponível em: www.ibge.gov.br Acesso em: setembro/ 02 .

Itaipuaçu: paraíso esquecido. (1996) Jornal O Dia. Grande Niterói, 22 de setembro, 1996.

Lins-de-Barros, F. M.; Muehe, D.; Roso R. H. (2003) Erosão e Danos na Orla Costeira do Município de Maricá, Rio de Janeiro. II Congresso de Planejamento e Gestão das Zonas Costeiras dos Países de Expressão Portuguesa, Recife, CD.

Lins-de-Barros, F. M. (2005) Risco e Vulnerabilidade à erosão costeira no Município de Maricá, Rio de Janeiro. Dissertação de Mestrado. Pós-Graduação em Geografia - UFRJ, Rio de Janeiro, 147p.
Morton, R. (2002) Factors Controlling Storm Impacts on Coastal Barriers and Beach - A Preliminary Basis for Near Real-Time Forecasting. Journal of Coastal Research, Florida 18 (3): 486-501.

Muehe, D. (2001) Critérios Morfodinâmicos para o Estabelecimento de limites da Orla Costeira para fins de Gerenciamento. Revista Brasileira de Geomorfologia, 2 (1): 35-44.

Muehe, D.; Valentini, E. (1998) O Litoral do Estado do Rio de Janeiro: uma caracterização físico-ambiental. Ed. FEMAR. Rio de Janeiro: 99p.(Footnotes)

Obs: Os perfis transversais foram cedidos pela professora Josefa Guerra do Departamento de Oceanografia da UERJ e pelo professor Guilherme Fernandez do Laboratório de Geologia Marinha da UFF. 